\title{
Fate of aqueous iron leached from tropospheric aerosols during atmospheric acidic processing: a study of the effect of humic-like substances
}

\author{
J. Borgatta \& J. G. Navea \\ Chemistry Department, Skidmore College, USA
}

\begin{abstract}
Humic-like substances (HULIS) are complex organic molecules that can be found in the atmosphere as components of tropospheric aerosols or suspended in atmospheric water. HULIS are chelating agents and oxidation-reduction species, therefore these substances can affect the availability of aqueous iron, a heavy metal commonly leached from atmospheric particulate matter upon acidic processing. Specifically, chelating properties allow HULIS to remove aqueous iron from atmospheric water, while their redox properties can alter iron speciation. Ultimately, wet deposition of soluble iron can be influenced not only by HULIS but also by other ubiquitous atmospheric cations. In this work, we investigate the effect of HULIS on iron leached from atmospheric particles in the presence of aluminium ions, an environmentally abundant cation also chelated by HULIS. Colorimetric methods were used to examine the cation exchange (CE) of aluminium ions with both iron (II) and (III) ions in humic acids, a model system for HULIS. An effective chelation of aqueous phase iron with humic acids was observed during suspension experiments, with aqueous iron removed from aqueous phase into a HULIS complex. In addition, the redox properties of humic acids showed no oxidation of iron (II) after chelation by humic acid, but a fraction of iron (III) was reduced into the more bioavailable iron (II). Cation exchange with aluminium suggests that bioavailable iron (II) ions chelate with HULIS in a combination of exchangeable and inexchangeable iron, with a higher proportion of exchangeable iron incidence. Additionally, HULIS interaction with iron (III) ions shows chelating properties as well a reduction potential, producing aqueous and chelated iron (II) ions.

Keywords: humic-like substances, cation exchange, iron mobility, chelation.
\end{abstract}




\section{Introduction}

In recent years it has become increasingly clear that atmospheric organic substances, in particular water soluble compounds, significantly impact the properties of tropospheric aerosols [1]. One of the most ubiquitous classes of water-soluble organic compounds in the atmosphere are HUmic-LIke Substances (HULIS) [2, 3]. While lighter in molecular weight than soil and aquatic humic substances, HULIS present many characteristics that resemble aquatic humic acids [4]. Like aquatic and terrestrial humic acids, HULIS are polymeric, polyacidic materials, containing a multicomponent mixture of aromatic and aliphatic compounds with carbonyl, hydroxyl, methoxyl, and carboxyl terminal groups [4]. Taraniuk and collaborators found that HULIS, like humic acids, are powerful chelating agents, impacting the chemistry of aerosol particles [5]. Additionally, terrestrial and aqueous humic substances are dominant redox active [6]; thus, it is supposed that HULIS also play an important role in reduction-oxidation mechanisms of atmospheric pollutants [6]. Yet, many HULIS environmental implications for trace atmospheric metals, such as heavy metal mobility [7], ligand promoted aerosol dissolution [8], and the redox effect [6], have not yet been explored.

The acidic functional groups of HULIS can bind to a variety of metals ions. This chelating property is particularly important for iron, a limiting nutrient for phytoplankton in the ocean $[9,10]$. Chen and Grassian proposed that ligandpromoted solubility of iron from atmospheric aerosols may play a significant role in mobilizing Fe from atmospheric dust compared with acidic processing alone [8]. Ultimately, van der Perk suggests that the humic-metal complexation enhances metal solubility [11], effectively partitioning heavy metals from tropospheric aerosols into atmospheric water. Thus, HULIS strong chelating functional groups may influence the ligand promoted solubility and further mobility of iron in tropospheric aqueous systems [12]. However, the transport and binding strength of the HULIS-Fe system is closely dependent on the relative replaceability of exchangeable cations, as described by Scheffer and Schachtschabel [13]. For instance, cation $\mathrm{Fe}^{3+}$ chelates to HULIS terminal groups with a slightly higher strength than that of $\mathrm{Al}^{3+}$, and overall higher strength $\mathrm{Fe}^{2+}$ binding to HULIS, approximately following the stability order of $\mathrm{Fe}^{3+}>\mathrm{Al}^{3+}>$ $\mathrm{Fe}^{2+}[13]$. Thus, a system with large excess of $\mathrm{Al}^{3+}$ can effectively displace any exchangeable $\mathrm{Fe}^{2+}$ complexated by HULIS, but might not be as effective to exchange with $\mathrm{Fe}^{3+}$. Yet, metal binding to HULIS can take place on inexchangeable sites [14], making the cation exchange (CE) process more convoluted.

In addition to the metal binding, HULIS are important redox agents [6]. In fact, electrochemical potentials determined by Aeschbacher and collaborators suggest that humic substances will be primarily reducing agents to iron [6]. While $\mathrm{Fe}^{3+}$ is the most abundant species of iron in tropospheric aerosols $[8,12]$, the presence of HULIS in atmospheric water can reduce iron to bivalent species, which is more bioavailable. Although the reduced form of iron can be exchanged by surrounding $\mathrm{Al}^{3+}$ in the aqueous phase, there are only a few investigations on the influence of 
$\mathrm{Fe}^{2+}$ and $\mathrm{Fe}^{3+}$ binding to organic substances under atmospherically relevant conditions [15]. In order to better understand the redox effect of HULIS on atmospheric aqueous iron, along with the effect of $\mathrm{Al}^{3+}$, we carried out cation exchange studies with $\mathrm{Al}^{3+}$ under atmospherically relevant conditions for both $\mathrm{Fe}^{3+}$ and $\mathrm{Fe}^{2+}$ on humic acids, a proxy for atmospheric HULIS.

\section{Experimental section}

\subsection{Materials}

The HULIS solution was prepared by suspending $10.0 \mathrm{mg}$ of humic acid (HA) (Sigma-Aldrich), in a $10.0 \mathrm{~mL}$ acidic solution of iron standard. Standard solutions of $\mathrm{Fe}^{3+}$ were prepared by dissolving iron (III) nitrate nonahydrated $\left(\mathrm{Fe}\left(\mathrm{NO}_{3}\right)_{3}\right) \cdot 9 \mathrm{H}_{2} \mathrm{O}$ (Sigma-Aldrich), into a solution of nitric acid to the desired final concentration. The $\mathrm{Fe}^{2+}$ standards were prepared from a $1000 \mathrm{ppm}$ stock solution of $\mathrm{Fe}^{2+}$, obtained by dissolving primary standard $\mathrm{Fe}\left(\mathrm{NH}_{4}\right)_{2}\left(\mathrm{SO}_{4}\right)_{2} \cdot 6 \mathrm{H}_{2} \mathrm{O}$ (SigmaAldrich) in an aqueous $0.01 \mathrm{M} \mathrm{HCl}$ solution. All HULIS solutions on iron standard were prepared to a final $\mathrm{pH}$ of 4 .

Cation exchange was carried out by adding aluminium chloride, $\mathrm{AlCl}_{3}$ (AlphaAesar), in a large excess, for a final concentration of $0.1 \% \mathrm{w} / \mathrm{w}$ in $\mathrm{Al}^{3+}$. The final solution was acidified to a final $\mathrm{pH}$ of 2 .

\subsection{Methods}

HULIS suspension on iron standards were incubated at room temperature overnight and non-chelated aqueous iron was selectively analysed colorimetrically with o-phenanthroline (Alpha-Aesar) for $\mathrm{Fe}^{2+}$ and potassium thiocyanate (SigmaAldrich) for $\mathrm{Fe}^{3+}$, forming the absorbing complexes shown in reactions (1) and (2) (vide infra). Interferences from HULIS chromophores are within the margin of error of the methods, as all solutions are diluted 10 times upon analysis, which minimizes any humic substance interference. In addition, both o-phenanthroline and thiocyanate iron complexes have a maximum of absorption at $525 \mathrm{~nm}$ and 490 $\mathrm{nm}$, respectively, well above the maximum of absorption of soluble humic acid at $220 \mathrm{~nm}$. The analysis of $\mathrm{Fe}^{3+}$ with potassium thiocyanate showed a slight HULIS interference, although quantification was still possible under experimental conditions. Non-chelated $\mathrm{Fe}^{2+}$ is selectively analysed via colorimetry, without interference from iron chelated by HULIS, as the $\left\{\right.$ HULIS- $\left.\mathrm{Fe}^{2+}\right\}$ and $\{$ HULIS$\mathrm{Fe}^{3+}$ \} complexes are favoured over the o-phenanthroline complex with $\mathrm{Fe}^{2+}$ and thiocyanate complex with $\mathrm{Fe}^{3+}$. The extraction of iron from HULIS by the colorimetric ligand has been shown to be slow, allowing the analysis of only aqueous iron (II) [16]:

$$
\begin{gathered}
\mathrm{Fe}^{2+}(a q)+3 \mathrm{o}-\text { phen }(a q) \rightleftharpoons\left\{\mathrm{Fe}(\mathrm{o}-\text { phen })_{3}\right\}^{2+}(a q) \\
\mathrm{Fe}^{3+}(a q)+\mathrm{SCN}^{-}(a q) \rightleftharpoons\{\mathrm{FeSCN}\}^{2+}(a q)
\end{gathered}
$$


The colorimetric analysis of humic acid samples on iron standards after overnight passivation allowed the evaluation of the HULIS-iron complex formation.

To investigate the $\mathrm{CE}, \mathrm{AlCl}_{3}$ was added to the HULIS-Fe complex solutions until a final concentration of $0.1 \% \mathrm{w} / \mathrm{w}$ of $\mathrm{Al}^{3+}$. Aluminium binds strongly with HULIS. In the presence of an excess of aluminium, the CE leads to the following reaction:

$$
\left\{\mathrm{HULIS}-\mathrm{Fe}^{\mathrm{n}+}\right\}(a q)+\mathrm{Al}^{3+}(a q) \rightleftharpoons\left\{\mathrm{HULIS}-\mathrm{Al}^{3+}\right\}(a q)+\mathrm{Fe}^{\mathrm{n}+}(a q)
$$

where $\mathrm{n}$ is the oxidation state of iron $(2+$ or $3+)$. Reaction (3) leaves iron available in aqueous phase for colorimetric analysis with o-phenanthroline or potassium thiocyanate (reactions (1) and (2)). Exchanged iron was determined immediately after the addition of $\mathrm{Al}^{3+}$, as cation exchange takes place instantaneously [11]. However, based on the stability order of the HULIS-metal complex (vide supra) [13], reaction (3) is not favoured for iron in the oxidation state $n=3+$, limiting the concentrations of $\mathrm{Fe}^{3+}$ exchanged. Finally, for the $\mathrm{CE}$ reaction (3) to be analytically useful, the concentration of $\mathrm{Al}^{3+}$ needs to be in excess, so the equilibrium is displaced towards the products. The $\mathrm{pH}$ of $\mathrm{CE}$ used for all the iron concentrations examined was $\mathrm{pH}=2$, acidified by the hydrolysis of $\mathrm{AlCl}_{3}$.

\section{Results and discussion}

\subsection{Characterization of HULIS Model System and HULIS-metal binding}

The solutions of HULIS, as well as HULIS treated in an iron standard solution before and after cation exchange (CE) with aluminium, were dried and analysed using an attenuated total reflection (ATR), in a germanium crystal (Pike Technologies), with a Fourier transformed infrared (FTIR) spectrometer (Thermo, 6700). A thin film of the humic sample, with and without metal complexation, were prepared by applying the aqueous sample onto the ATR crystal and placed in a dry air purged sample compartment; as water evaporated, a thin film of the HULIS/HULIS-metal sample was homogeneously deposited on the surface of the ATR crystal. Figure 1 shows three different FTIR spectra: humic acid with no iron or aluminium (HULIS), humic acid in a $15 \mathrm{ppm}$ solution of $\mathrm{Fe}^{2+}$ $\left(\mathrm{HULIS}+\mathrm{Fe}^{2+}\right.$ ), and the solution after CE $\left(\mathrm{HULIS}+\mathrm{Al}^{3+}\right)$. All FTIR spectra are averages of 100 scans with a $4 \mathrm{~cm}^{-1}$ resolution.

ATR-FTIR spectrum of the samples revealed a typical pattern of humic materials. The broad and intense peak ranging from 3100 to $3500 \mathrm{~cm}^{-1}$ is assigned to O-H stretching with inter- and intra-molecular hydrogen bonding characteristic of polymeric alcohols, phenols, and carboxylic acids $[4,17]$. The relatively high intensity of this $\mathrm{OH}$ band in the presence of aluminium indicates that humic materials are protonated due to the acidic environment during $\mathrm{CE}$ This equilibrium protonation can also be observed in the clear band at $2920 \mathrm{~cm}^{-1}$, assigned to C-H stretching vibration of aliphatic acids and in the band centred at $2474 \mathrm{~cm}^{-1}$ for protonated carboxylic acids [4]. 


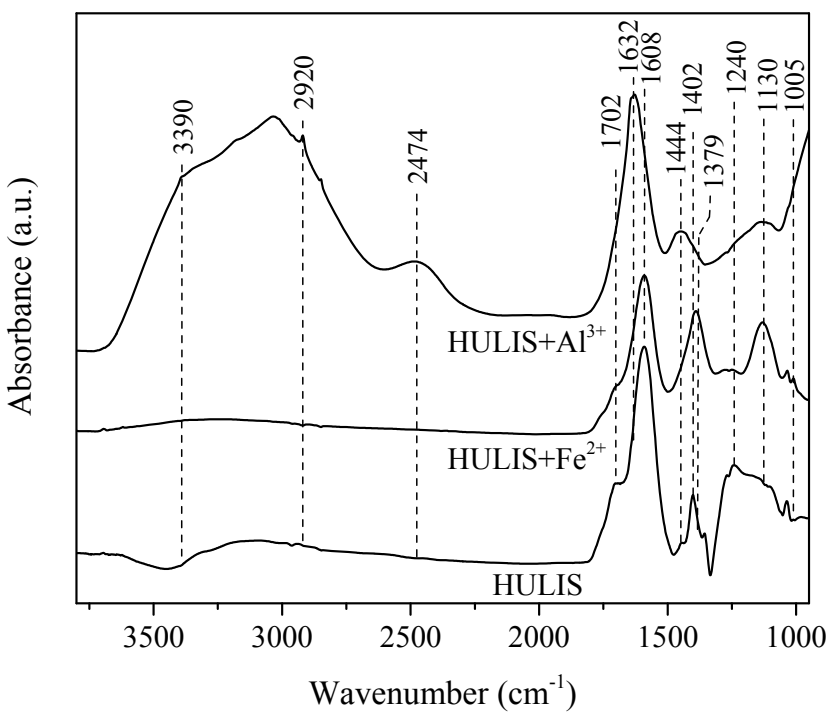

Figure 1: Infrared spectra of dried HULIS solutions (ATR-FTIR). Bottom spectrum: aqueous phase of HULIS; middle spectrum: HULIS in a 15 ppm solution of $\mathrm{Fe}^{2+}$ standard; top spectrum: HULIS after cation exchange with $\mathrm{Al}^{3+}$.

The carboxylic band at $1608 \mathrm{~cm}^{-1}$ shows a shift of $\Delta v=24 \mathrm{~cm}^{-1}$ in excess of aluminium, indicating that metal chelation takes place with binding in the carboxylic group $[4,17]$. In addition, there is a significant shift $\left(\Delta v=42 \mathrm{~cm}^{-1}\right)$ in the $\mathrm{C}-\mathrm{H}$ aromatic ring stretch, at $1402 \mathrm{~cm}^{-1}$ [18], suggesting that aromatic rings also participate in the metal chelation process. Given the low concentrations of iron chelated in HULIS, no significant shifts are observed on the carboxylic or aromatic bands. However, an iron chelation is observed in a significant $\mathrm{Fe}-\mathrm{O}$ band growth at $1379 \mathrm{~cm}^{-1}$ along with a small but observable band at $1030 \mathrm{~cm}^{-1}$ assigned to the $\mathrm{Fe}-\mathrm{OH}$ stretch [19]. In addition, the disappearance of the peak at $1240 \mathrm{~cm}^{-1}$ as metals are added to the HULIS mixture indicates that $\mathrm{OH}$ in phenyl groups also participate in the chelation of metals $[18,20]$. The peak assignment for HULIS solutions is summarized in Table 1.

Figure 2 shows the UV-Vis spectrum (Perking-Elmer Lambda 35) of the humic fractions with and without metal treatment. In general, the HULIS proxy shows a strong absorbance, mainly in the UV range, from $190 \mathrm{~nm}$ to $400 \mathrm{~nm}$, due to the presence of aromatic chromophores. Upon addition of metal, the UV absorptivity around $220 \mathrm{~nm}$ decreased, characteristic of the $\pi-\pi^{*}$ transitions in substituted benzenes or polyphenols [22]. This relative loss of absorptivity indicates that aromatic $\mathrm{C}=\mathrm{C}$ undergoes distortion and electron density loss during metal binding. Some red shift is also observed as shoulders when iron and aluminium are chelated by the humic substance, supporting that the aromatic rings in HULIS also participate in metal chelation, as suggested by the FTIR spectra. 
Table 1: ATR-FTIR peak assignments for HULIS samples.

\begin{tabular}{ccc}
\hline Frequency $\left(\mathbf{c m}^{-\mathbf{1}}\right)$ & Assignment & Reference \\
\hline $\mathbf{3 3 9 0}$ & H-bonded OH & {$[4,17,21]$} \\
$\mathbf{2 9 2 0}$ & C-H stretching of aliphatic acids & {$[4,17,21]$} \\
$\mathbf{2 4 7 4}$ & $\mathrm{O}-\mathrm{H} v_{\text {as }}(\mathrm{COOH})$ & {$[17,20]$} \\
$\mathbf{1 7 0 2}$ & $\mathrm{C}=\mathrm{O} v_{\text {as }}(\mathrm{COOH})$ & {$[4,17,21]$} \\
$\mathbf{1 6 0 8} / \mathbf{1 6 3 8}$ & $\mathrm{C}=\mathrm{O} v_{\text {as }}(\mathrm{COO})$ & {$[17]$} \\
$\mathbf{1 4 5 0}-\mathbf{1 3 7 0}$ & $\mathrm{C}-\mathrm{H}$ ring stretch & {$[18]$} \\
$\mathbf{1 3 7 9}$ & Fe-O stretch & {$[19]$} \\
$\mathbf{1 2 4 0}$ & Ph-OH and Ph-COOH stretch & {$[20,21]$} \\
$\mathbf{1 1 3 0}$ & $\mathrm{C}-\mathrm{O}(\mathrm{C}=\mathrm{O}) v_{\text {as }}$ & {$[21]$} \\
$\mathbf{1 0 3 0}$ & Fe-O stretch & {$[19]$} \\
$\mathbf{1 0 0 5}$ & C-H Polysaccharides stretch & {$[4,21]$} \\
\hline
\end{tabular}

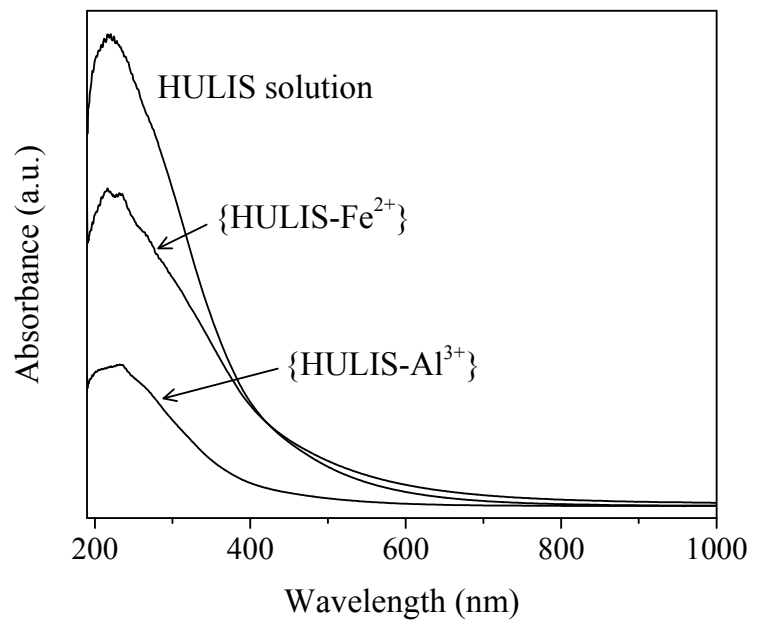

Figure 2: UV-Vis spectra of humic solutions. Aqueous phase humic acid (HULIS solution); humic acid in $15 \mathrm{ppm}$ of iron (II) standard $\left(\left\{\right.\right.$ HULIS- $\left.\left.\mathrm{Fe}^{2+}\right\}\right)$; humic acid after cation exchange with excess of aluminium (III) ( $\left\{\right.$ HULIS-Al $\left.{ }^{3+}\right\}$ ).

An elemental analysis of the organic sample ( $\mathrm{CHN}$ analyzer, Costech Instruments) revealed an organic composition of the humic substance used as HULIS proxy of $(38 \pm 2) \%,(3.34 \pm 0.08) \%,(0.84 \pm 0.05) \%$, in carbon, hydrogen, and nitrogen, respectively. The $\mathrm{C} / \mathrm{H}$ and $\mathrm{C} / \mathrm{N}$ rations are similar to those proposed by the Steelink humic monomer [23]. In addition, X-ray fluoresce (XRF) spectroscopy (Bruker) showed the presence of trace metals in the untreated sample, with a relatively large presence of iron. Analysis with atomic absorption spectrophotometer (Perkin Elmer) showed $(1.07 \pm 0.03) \%$ total iron, with estimated concentration of calcium, strontium, and titanium $<0.5 \%$, and copper, nickel, zinc, phosphorous and sulphur $<0.05 \%$. 


\subsection{HULIS chelation of iron}

As observed by spectroscopic evidence in the preceding section, more than one functional site of HULIS chelates both iron and aluminium. Under atmospherically acidic conditions of $\mathrm{pH}$ below 4 [24], the moderately acidic functional groups of HULIS tend towards protonation, with a variable negative density charge [11]. In addition, at $\mathrm{pH}$ below 4, aqueous phase aluminium is predominantly in the $\mathrm{Al}^{3+}$ form [11]. These conditions promote the $\mathrm{CE}$ as described by reaction (3), in which a large excess of $\mathrm{Al}^{3+}$ will exchange with exchangeable $\mathrm{Fe}^{2+}$ or $\mathrm{Fe}^{3+}$. Cation exchange is a relatively fast process, which allows for the instantaneous analysis of iron in solution upon CE.

Figure 3 shows the fraction of $\mathrm{Fe}^{2+}$ standard that remains free after chelation by HULIS with respect of the initial concentration of $\mathrm{Fe}^{2+}$ standard $\left(\left[\mathrm{Fe}^{2+}\right]_{0}\right)$. It is clearly observed that, a significant fraction of the aqueous $\mathrm{Fe}^{2+}$ remains in solution as free $\mathrm{Fe}^{2+}$ after the equilibrium in reaction (4) has been reached:

$$
\operatorname{HULIS}(a q)+\mathrm{Fe}^{2+}(a q) \rightleftharpoons\left\{\operatorname{HULIS}-\mathrm{Fe}^{2+}\right\}(a q)
$$

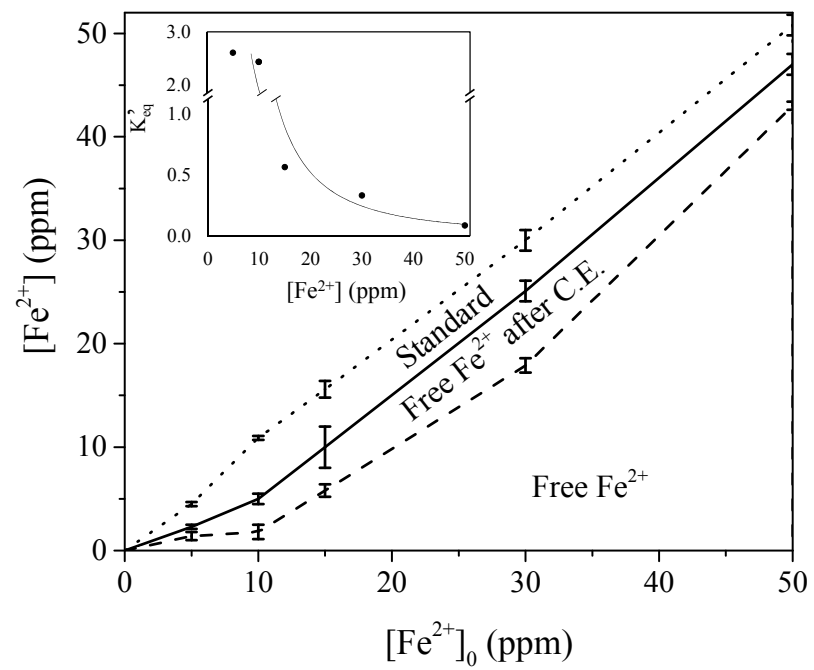

Figure 3: Free and exchangeable $\mathrm{Fe}^{2+}$ from a HA suspension on $\mathrm{Fe}^{2+}$ standards. The area under the dashed line represents the concentration of $\mathrm{Fe}^{2+}$ remaining in solution (free $\mathrm{Fe}^{2+}$ ) after HULIS chelation of available iron. The area under the solid line represents free $\mathrm{Fe}^{2+}$ after the addition of $0.1 \% \mathrm{w} / \mathrm{w}$ of $\mathrm{Al}^{3+}$, once $\mathrm{CE}$ has been completed. Finally, the area under the dotted line represents the total $\mathrm{Fe}^{2+}$ present in solution before the addition of HULIS. The insert represent the ratio between the concentration of $\left\{\right.$ HULIS-Fe ${ }^{2+}$ \} and free $\mathrm{Fe}^{2+}$. Each point is the mean of triplicate measurements and the error bars represent the standard deviation. 
As the HULIS binding sites get occupied, the formation of the $\left\{\mathrm{HULIS}-\mathrm{Fe}^{2+}\right\}$ complex reaches a limit given by the saturation of HULIS chelating sites. Under our experimental conditions, the HULIS chelating capacity reaches a maximum at a $\left[\mathrm{Fe}^{2+}\right]_{0}$ threshold of around $10 \mathrm{ppm}$. Above this threshold concentration, a constant amount of $\mathrm{Fe}^{2+}$ will complex with HULIS.

Because HULIS is present in a relatively large concentration $(1000 \mathrm{mg} / \mathrm{L})$ with respect of $\left[\mathrm{Fe}^{2+}\right]_{0},[$ HULIS] remains relatively constant over the course of the reaction. Thus, the equilibrium constant for equation (4) can be expressed as $\mathrm{K}_{\mathrm{eq}}^{\prime}$, or the ratio between of remaining aqueous $\mathrm{Fe}^{2+}$ (free $\mathrm{Fe}^{2+}$ ) with respect of [HULIS $\left.-\mathrm{Fe}^{2+}\right]$ :

$$
\mathrm{K}_{\mathrm{eq}}=\frac{\left[\text { HULIS }-\mathrm{Fe}^{2+}\right]}{[\text { HULIS }]\left[\mathrm{Fe}^{2+}\right]} \Rightarrow \mathrm{K}_{\mathrm{eq}}^{\prime}=[\text { HULIS }] \mathrm{K}_{\mathrm{eq}}=\frac{\left[\text { HULIS }-\mathrm{Fe}^{2+}\right]}{\left[\mathrm{Fe}^{2+}\right]}
$$

Upon saturation of HULIS chelating sites, the concentration of $\mathrm{Fe}^{2+}$ in aqueous phase $\left(\left[\mathrm{Fe}^{2+}\right]\right)$ increases with $\left[\mathrm{Fe}^{2+}\right]_{0}$, and thus the $\mathrm{K}_{\mathrm{eq}}^{\prime}$ decreases. The change in the equilibrium constant is, therefore, driven by the ratio between the concentration of $\left\{\right.$ HULIS- $\left.\mathrm{Fe}^{2+}\right\}$ and free $\mathrm{Fe}^{2+}\left(\mathrm{K}_{\mathrm{eq}}^{\prime}\right)$ and it is represented in the insert of Figure 3.

This HULIS-Fe ${ }^{2+}$ complex is highly soluble, increasing the environmental mobility of iron. Therefore, HULIS complexing of iron is a significant factor in the transport and wet deposition of atmospheric iron. However, based on the Scheffer and Schachtschabel [13] chelate stability, the ubiquitous $\mathrm{Al}^{3+}$ can break the HULIS-Fe ${ }^{2+}$ interaction for the most favoured $\left\{\right.$ HULIS- $\mathrm{Al}^{3+}$ \}, particularly under $\mathrm{Al}^{3+}$ excess, a common environmental occurrence during tropospheric aerosol dissolution.

Figure 3 shows the relative increase of aqueous free $\mathrm{Fe}^{2+}$ after the addition of $\mathrm{Al}^{3+}$ to the $\left\{\right.$ HULIS-Fe ${ }^{2+}$ \} solution. However, the amount of $\mathrm{Fe}^{2+}$ measured after $\mathrm{CE}$ (solid line) is less than the original amount of $\mathrm{Fe}^{2+}$ added (dotted line). Since no $\mathrm{Fe}^{3+}$ was detected, suggesting no oxidation of $\mathrm{Fe}^{2+}$ by HULIS, some $\mathrm{Fe}^{2+}$ must remain chelated in HULIS. This indicates two types of binding sites, one exchangeable and one inexchangable. The inexchangable sites of HULIS are favoured as suggested by the binding observed for $5 \mathrm{ppm}$ of $\mathrm{Fe}^{2+}$ solutions, where exchanged $\mathrm{Fe}^{2+}$ was only (1.2 \pm 0.2$)$ ppm, or around $27 \%$ of the initial aqueous $\mathrm{Fe}^{2+}$. In general, the inexchangable iron in HULIS, $\left[\mathrm{Fe}^{2+}\right]_{\text {inx }}$, seems to be fairly constant as evidenced by the relatively constant slope of free iron after C.E, particularly after the $10 \mathrm{ppm}$ threshold. Under our experimental conditions, $\left[\mathrm{Fe}^{2+}\right]_{\text {inx }}$ reaches a maximum of $5 \mathrm{ppm}$ for every $\left[\mathrm{Fe}^{2+}\right]_{0}$ examined, after which inexchangable sites are no longer available.

Increasing the initial concentration of aqueous $\mathrm{Fe}^{2+}$ to concentration above a threshold of $10 \mathrm{ppm}$, where both HULIS sites become saturated, showed a relatively higher iron recovery $\left(\phi_{R}\right)$ :

$$
\phi_{R} \approx \frac{\left[\mathrm{Fe}^{2+}\right]_{0}-\left[\mathrm{Fe}^{2+}\right]_{\text {inx }}}{\left[\mathrm{Fe}^{2+}\right]_{0}}
$$


Where iron recovery is the ratio of the concentration of free $\mathrm{Fe}^{2+}$ after $\mathrm{CE}$ divided by the initial concentration of $\mathrm{Fe}^{2+},\left[\mathrm{Fe}^{2+}\right]_{0}$. At relatively higher concentrations of initial $\mathrm{Fe}^{2+}$, the percentages of exchanged iron rose to $29 \%, 65 \%$, $75 \%$ and $92 \%$ for initial $\mathrm{Fe}^{2+}$ concentrations of $10 \mathrm{ppm}, 15 \mathrm{ppm}, 30 \mathrm{ppm}$, and 50 ppm, respectively. Clearly, $\left[\mathrm{Fe}^{2+}\right]_{\text {inx }}$ depends on the concentration of HULIS. Higher concentrations of HULIS in atmospheric water will increase the inexchangable sites available to irreversible chelate $\mathrm{Fe}^{2+}$. Thus, it can easily be shown that the $\mathrm{CE}$ yield can be expressed by the logical statement in equation (7):

$$
\left[\mathrm{Fe}^{2+}\right]_{0}>\left[\mathrm{Fe}^{2+}\right]_{\text {inx }} \leftrightarrow \phi_{R}=1-\frac{\left[\mathrm{Fe}^{2+}\right]_{\text {inx }}}{\left[\mathrm{Fe}^{2+}\right]_{0}}
$$

Equation (7) implies that as $\left[\mathrm{Fe}^{2+}\right]_{0}$ increases, the iron recovery will be larger.

\subsection{HULIS redox of iron}

Incubation of HULIS with $\mathrm{Fe}^{2+}$ yields only $\mathrm{Fe}^{2+}$, either chelated or free. In contrast, suspension of HULIS in $\mathrm{Fe}^{3+}$ standard yields both $\mathrm{Fe}^{2+}$ and $\mathrm{Fe}^{3+}$. Table 2 shows the effect of HULIS proxy suspension in a solution of $18 \mathrm{ppm}$ of $\mathrm{Fe}^{3+}$ standard. Here, HULIS reduction potential is enough to form free $\mathrm{Fe}^{2+}$.

Table 2: $\quad$ HULIS on $\mathrm{Fe}^{3+}$ standard.

\begin{tabular}{|c|c|c|c|c|}
\hline $\begin{array}{l}\left(\mathrm{Fe}^{3+}\right)_{0} \\
(\mathrm{ppm})\end{array}$ & $\begin{array}{c}\left(\mathrm{Al}^{3+}\right) \\
(\% \mathbf{w} / \mathbf{w})\end{array}$ & $\begin{array}{c}\text { Free }\left(\mathrm{Fe}^{3+}\right) \\
(\mathrm{ppm})\end{array}$ & $\begin{array}{c}\text { Free }\left(\mathrm{Fe}^{2+}\right) \\
(\mathrm{ppm})\end{array}$ & $\begin{array}{c}\text { Free }(\mathrm{Fe})_{\text {total }} \\
(\mathrm{ppm})\end{array}$ \\
\hline \multirow{2}{*}{18} & 0 & $1.8 \pm 0.2$ & $1.2 \pm 0.4$ & $2.0 \pm 0.6$ \\
\hline & 0.1 & $2.1 \pm 0.2$ & $2.4 \pm 0.7$ & $4.5 \pm 0.9$ \\
\hline \multirow{2}{*}{30} & 0 & $0.12 \pm 0.09$ & $1.1 \pm 0.1$ & $1.2 \pm 0.2$ \\
\hline & 0.1 & $2.4 \pm 0.9$ & $5.6 \pm 0.5$ & $7.9 \pm 1$ \\
\hline \multirow{2}{*}{50} & 0 & $0.60 \pm 0.09$ & $2.5 \pm 0.5$ & $3.1 \pm 0.6$ \\
\hline & 0.1 & $3.0 \pm 0.7$ & $6.7 \pm 0.3$ & $9.7 \pm 1$ \\
\hline
\end{tabular}

Once again, HULIS does not chelate all the amount of iron available. Before $\mathrm{CE}$, a significant fraction of $\mathrm{Fe}^{3+}$ standard, $\left[\mathrm{Fe}^{3+}\right]_{0}$, is chelated by HULIS. In addition, $4-7 \%$ of the $\mathrm{Fe}^{3+}$ standard is converted into free $\mathrm{Fe}^{2+}$. The chelation and exchange of iron by HULIS can be summarized as follows:

$$
\begin{gathered}
\text { HULIS }(\mathrm{aq})+\mathrm{Fe}^{3+}(\mathrm{aq}) \rightarrow\left\{\text { HULIS }-\mathrm{Fe}^{3+}\right\}(\mathrm{aq}) \\
\text { HULIS }(\mathrm{aq})+\mathrm{Fe}^{3+}(\mathrm{aq}) \rightarrow \mathrm{Fe}^{2+}(\mathrm{aq})+[\text { HULIS }]^{+}(\mathrm{aq}) \\
\operatorname{HULIS}(\mathrm{aq})+\mathrm{Fe}^{2+}(\mathrm{aq}) \rightarrow\left\{\text { HULIS }-\mathrm{Fe}^{2+}\right\}(\mathrm{aq}) \\
\left\{\text { HULIS }-\mathrm{Fe}^{n+}\right\}(\mathrm{aq})+A l^{3+}(a q) \rightleftharpoons\left\{\text { HULIS }-\mathrm{Al}^{3+}\right\}(\mathrm{aq})+\mathrm{Fe}^{n+}
\end{gathered}
$$

In equation (9) HULIS transfers an electron to reduce $\mathrm{Fe}^{3+}$, producing $\mathrm{Fe}^{2+}$ which can be chelated by HULIS. As a consequence, the charge density of HULIS becomes less negative, diminishing its capacity to effectively bind iron. However, given the higher stability of the $\left\{\right.$ HULIS- $\left.-\mathrm{Fe}^{3+}\right\}$, iron recovery is lower than 
observed in the presence of only $\mathrm{Fe}^{2+}$, around $25 \%$ total iron recovery, which is significantly lower than the recovery observed for $\mathrm{Fe}^{2+}$ alone. This is supported by the low amount of $\mathrm{Fe}^{3+}$ exchanged in every concentration examined, consistent with the chelate stability observations of Scheffer and Schachtschabel [13]. Given the large excess of $\mathrm{Al}^{3+}$, this low CE suggests that $\mathrm{Fe}^{3+}$ binds to HULIS stronger than $\mathrm{Al}^{3+}$. Most iron exchanged corresponds to the reduced species of iron, $\mathrm{Fe}^{2+}$. In fact, the concentration of aqueous $\mathrm{Fe}^{2+}$ increases significantly after $\mathrm{CE}$ with $\mathrm{Al}^{3+}$.

As the $\left\{\right.$ HULIS $-\mathrm{Fe}^{3+}$ \} complex is more stable, a higher HULIS induced mobility is expected for $\mathrm{Fe}^{3+}$ than that for $\mathrm{Fe}^{2+}$. In fact, given the values of $\left[\mathrm{Fe}^{2+}\right]_{\text {inx }}(5 \mathrm{ppm})$ under our experimental conditions, it can be assumed that $\mathrm{Fe}^{3+}$ is the larger fraction of inexchangable iron that results from the interaction of HULIS with $\mathrm{Fe}^{3+}$ standard. However, HULIS can also decrease the relative concentration of $\mathrm{Fe}^{3+}$ in atmospheric water in favour of $\mathrm{Fe}^{2+}$.

\section{Atmospheric implications}

In the past decade, it has been suggested that atmospheric acidic processing of tropospheric aerosols leaches mostly $\mathrm{Fe}^{3+}$ into atmospheric water [25]. However, the presence of HULIS suggests that a fraction of aqueous $\mathrm{Fe}^{3+}$ leached from atmospheric dust will undergo reduction to form the bioavailable $\mathrm{Fe}^{2+}$. In addition, the higher solubility of the HULIS-Fe complexes can induce further aerosol dissolution. Thus, the presence of HULIS will not only increase the concentration of aqueous iron in atmospheric water but increase the transport of iron species in the troposphere. Ultimately, since $\mathrm{Fe}^{2+}$ is bioavailable and a limiting phytoplankton nutrient, during atmospheric acidic processing HULIS can induce and/or boost plankton blooms.

Nonetheless, environmental factors can directly impact the role of HULIS in the transport, chelation, and reduction of iron. Cations such as $\mathrm{Al}^{3+}$, also leached from acidic dissolution of atmospheric dust, induce cation exchange, which partition $\mathrm{Fe}^{2+}$ to the aqueous phase. Given that both metals, aluminium and iron, are common components of atmospheric dust, HULIS will induce a relatively larger concentration of $\mathrm{Fe}^{2+}$ than initially expected in the aqueous phase of tropospheric water.

\section{References}

[1] S. Fuzzi, M. O. Andreae, B. J. Huebert, M. Kulmala, T. C. Bond, M. Boy, S. J. Doherty, A. Guenther, M. Kanakidou, K. Kawamura, V. M. Kerminen, U. Lohmann, L. M. Russell and U. Pöschl, "Critical assessment of the current state of scientific knowledge, terminology, and research needs concerning the role of organic aerosols in the atmosphere, climate, and global change," Atmos. Chem. Phys., pp. 2017-2038, 2006.

[2] S. Decesari, S. Fuzzi, M. C. Facchini, M. Mircea, L. Emblico, F. Cavalli, W. Maenhaut, X. Chi, G. Schokolnik, A. Falkovich, Y. Rudich, M. Claeys, V. Pashynska, G. Vas, I. Koutchev, R. Vermeylen, A. Hoffer, M. O. 
Andreae, E. Tagliavini, F. Moretti and P. Artaxo, "Characterization of the organic composition of aerosols from Rondonia, Brazil, during the LBASMOCC 2002 experiment and its representation through model compounds," Atmos. Chem. Phys. , vol. 6, pp. 375-402, 2006.

[3] I. Salma, R. Ocskay and G. G. Láng, "Properties of atmospheric humic-like substances - water system," Atmos. Chem. Phys., vol. 8, pp. 2243-2254, 2008.

[4] E. R. Graber and Y. Rudich, "Atmospheric HULIS: How humic-like are they? A comprehensive and critical review," Atmos. Chem. Phys., vol. 6, pp. 729-753, 2006.

[5] I. Taraniuk, Y. Rudich and E. R. Graber, "Hydration-influenced sorption of organic compounds by model and atmospheric humic-like substances," Environ. Sci. Technol., vol. 43, pp. 1811-18-17, 2009.

[6] M. Aeschbacher, M. Sander and R. P. Schwarzenbach, "Novel electrochemical approach to assess the redox properties of humic substances," Environ. Sci. Tech., vol. 44, pp. 87-93, 2010.

[7] M. D. Paciolla, G. Davies and S. A. Jansen, "Generation of hydroxyl radicals from metal loaded humic acids," Environ. Sci. Technol., vol. 33, pp. 1814-1818, 1999.

[8] H. Chen and V. H. Grassian, "Iron dissolution of dust source materials during simulated acidic processing: The effect of sulfuric, scetic, and oxalic acids," Environ. Sci. Technol., vol. 47, pp. 10312-10321, 2013.

[9] J. H. Martin, "Glacial-interglacial CO2 change: The iron hypothesis," Paleoceanography, vol. 5, no. 1, pp. 1-13, 1990.

[10] J. K. Moore, S. C. Doney, D. M. Glover and I. Y. Fung, "Iron cycling and nutrient-limitation patterns in surface waters of the World Ocean," DeepSee Res. Part II-Top. Stud. Oceanogr., vol. 49, pp. 463-507, 2002.

[11] M. van der Perk, Soil and water contamination, Leiden, The Netherlands: CRC Press, 2014.

[12] H. Lippold, N. D. M. Evans, P. Warwick and H. Kupsch, "Competitive effect of iron (III) on metal complexation by humic substances: Characterization of ageing processes," Chemosphere, vol. 67, pp. 10501056, 2007.

[13] F. Scheffer and P. Schachtschabel, Lehrbuch der Bodenkunde, Stuttgart, Germany: Enke Verlag, 1989.

[14] P. Zhou, H. Yan and B. Gu, "Competitive complexation of metal ions with humic substances," Chemosphere, vol. 58, pp. 1327-1337, 2005.

[15] B. J. Holmes and G. A. Petrucci, "Water soluble oligomer formation from acid-catalized reactions of levoglucosan in proxies of atmospheric aqueous aerosols," Environ. Sci. Technol., vol. 40, pp. 4983-4989, 2006.

[16] N. Fujisawa, K. Furubayashi, M. Fukushima, M. Yamamoto, T. Komai, K. Ootsuka and Y. Kawabe, "Evaluation of iron (II)-binding abilities of humic acids by complexometric titrations using colorimetry with orthophenanthroline," Humic Sub. Res., vol. 8, pp. 1-6, 2011.

[17] G. Xiao-hong, C. Guang-hao and S. Chii, "ATR-FTIR and XPS study on the structure of complexes formed upon adsorption of simple organic acids 
on aluminum hydroxide," Journal of Environmental Sciences, vol. 19, pp. 438-443, 2007.

[18] J. Dorado, M. C. Zancada, G. Lamendros and C. López-Fando, "Changes in soil properties and humic substances after long term amendments with manure and crop in dryland farming systems," J. Plant Nutr. Sci., vol. 166, pp. 31-38, 2003.

[19] C. Colombo, G. Palumbo, V. M. Sellitto, C. Rizzardo, N. Tomasi, R. Pinton and S. Cesco, "Characteristics of insoluble, high molecular weight, ironhumic substances used as plant iron sources," Soil Sci. Soc. Am. J., vol. 76, pp. 1246-1256, 2011.

[20] S. Jayaganesh and V. K. Senthurpandian, "Extraction and characterization of humic and fulvic acids from latosols under tea cultivation in South India," Asian J. Earth Sci., vol. 3, no. 3, pp. 130-135, 2010.

[21] S. Cowen and H. A. Al-Abadleh, "DRIFTS studies on the photodegradation of tannic acid as a model for HULIS in atmospheric aerosols," Phys. Chem. Chem. Phys., vol. 11, pp. 7838-7847, 2009.

[22] C. Baduel, D. Voisin and J. L. Jaffrezo, "Comparison of analytical methods for humic like substances (HULIS) measurements in atmospheric particles," Atmos. Chem. Phys., vol. 9, pp. 5949-5962, 2009.

[23] C. Steelink, "Elemental characteristics of humic substances," in Humic Substances in Soil, Sediment, and Water, New York, Wiley, 1985, pp. 457476.

[24] J. H. Seinfeld and S. N. Pandis, Atmospheric Chemistry and Physics: From Air Pollution to Climate Change, Hoboken, N. J.: Wiley, 2006.

[25] P. Kyei, G. Rubasinghege and V. H. Graasian, "Assimilation of iron in the ocean: Acid promoted dissolution of nano and micro goethite in the presence of inorganic oxyanions," Abstr. Pap. Am. Chem. S., p. 241, 2011. 